\title{
Pediatric patients at a high risk of headache of ocular origin: the HAMS Score (Hyperopia, Astigmatism, Myopia, and Strabismus)
}

\author{
Paulo de Tasso Valença Veloso de Siqueira' ${ }^{1 D}$, Luciana Patrízia Alves de Andrade Valença ${ }^{1}$ (D), \\ Juliana Ramos de Andrade ${ }^{1}$ (D) , Marcelo Moraes Valença ${ }^{1,2}$ (iD)
}

${ }^{1}$ Universidade Federal de Pernambuco, Recife, Brazil

${ }^{2}$ Unimed Recife, Recife, Brazil

\section{$\triangle$}

Marcelo Moraes Valença mmvalenca@yahoo.com.br

Edited by: Mário Fernades Prieto Peres
Keywords:

Headache

Ocular diagnosis

Pediatric patients

Refractive Errors

Strabismus

Myopia

\begin{abstract}
Background

Pediatric patients identified at increased risk for headache due to ocular refractive errors were evaluated to produce a diagnostic tool called the HAMS score that will help establish the likelihood of headache due to refractive errors.

Methods

Data on the ocular diagnosis and headache complaints of 726 pediatric patients of both sexes were obtained from the medical records of an ophthalmological service in Brazil (Hospital de Olhos Santa Luzia). Age, use of glasses, and ocular diagnosis were also considered to create an index based on the number of ocular diagnoses in a given individual (HAMS score) to verify their association with the incidence of headache. Once the database was finalized, it was then analyzed to identify the variables capable of predicting the occurrence of headaches, following which a profile of those at the highest risk was produced by comparison.

Results

Only the ocular diagnosis was significantly associated with headache as a function of sex, age, use of glasses, farsightedness, astigmatism, myopia, and strabismus, indicating the relative impact of each ocular diagnosis on the probability of headache. According to the HAMS score, strabismus is more likely to have headache (5.21), followed by hyperopia (3.10), myopia (2.67), and, finally, astigmatism (1.86). The findings showed that the presence or absence of refraction errors and strabismus is predictive of the occurrence of headache, particularly in a small group of patients $(6.2 \%)$ where the probability of headache was $57.8 \%$. Such patients were characterized by being younger, having a combination of strabismus, hyperopia, and astigmatism, and already be using corrective lenses.

\section{Conclusion}

The index based on the most common ocular diagnoses (HAMS score) is effective, and it has practical application in identifying children and adolescent patients with a greater or lesser propensity for headaches of ophthalmic origin.
\end{abstract}




\section{Introduction}

For more than one century, the relationship between eye F and headache attacks has been studied. ${ }^{1-19}$ Headache episodes of ocular origin can occur as a local event triggering a primary headache attack such as migraine. ${ }^{20}$ The mechanisms involved in such cases are any affections that interfere with the correct functioning of the optical system, which might lead to a headache. This includes refraction errors (myopia, astigmatism, hyperopia), heterotropia (strabismus), inflammatory disease (keratitis, uveitis, scleritis), infections (corneal ulcers, conjunctivitis, endophthalmitis), and glaucoma (closed-angle, neovascular), as well as orbital pathologies (cellulitis, orbital pseudotumors, tendinitis), and any affection of the fifth cranial pair. ${ }^{21-26}$

Among children, the leading cause of headaches are migraine and tension-type headache, ${ }^{27-29}$ though they are considered to be fairly rare, occurring in $2-5 \%$ of those below the age of 15 years, with the peak incidence occurring between the ages of 10 and $15 .{ }^{30}$ Approximately $4.3 \%$ of the children and adolescents experience headaches by the age of two or three, with a gradual increase until they reach school age. ${ }^{31}$ In adolescents, the figures tend to surpass $50 \% .^{32}$

Below the age of 10 , primary headaches are generally more prevalent in males than in females, ${ }^{33}$ but the female sex usually predominates during adolescence. ${ }^{34}$ There is also an association with age itself, for complaints of headaches tend to increase as the children get older. $32,35,36$ However, the role of ocular causes in headache medicine, particularly in children and adolescents, is still controversial.

Parents and caretakers of children with headaches frequently suspect the origin to be refraction errors. ${ }^{37,38}$ However, corrective lenses usually do not change the characteristics or course of the headaches even when a refraction error is effectively diagnosed. ${ }^{39}$ For this reason, when a child experiences headaches, one of the most commonly consulted specialists is the ophthalmologist. ${ }^{38,40-44}$ The official word of the International Headache Society is that uncorrected refraction errors and heterotropia may cause headaches ${ }^{42}$ but their importance is enormously overestimated. Regarding heterotropia, it is read in the ICHD-3 that "there are a number of supportive cases for A11.3.5 Headache attributed to heterophoria or heterotropia but otherwise little evidence for this cause of headache. It has therefore been moved to the Appendix pending more formal study." 42

A case series of pediatric patients seen at an ophthalmology service with complaints of headache were analyzed with the aim of producing a useful diagnostic tool called the HAMS Heavy Score. This tool will help establish the likelihood of headache due to refractive errors and heterotropy and provides a checklist of attributes that may help identify pediatric patients at increased risk for ocular headache.

\section{Methods}

\section{Sample}

The present study included data from 726 patients, between 3 months and 19 years, brought to an ophthalmological service (Hospital de Olhos Santa Luzia) in Recife, Pernambuco, Brazil, between January and October of 2011 . The independent variables age, sex, use of glasses, headache complaint and ocular diagnosis, to create an index based on the number of diagnoses of hyperopia, astigmatism, myopia and strabismus on a given individual (HAMS Score) were considered to verify their association with the incidence of headaches. Table 1 shows the distribution of age and sex for the series obtained.

Table 1. Sex and age of the patients

\begin{tabular}{|c|c|c|c|c|c|c|}
\hline \multirow{3}{*}{ Age (years) } & \multicolumn{4}{|c|}{ Sex } & \multirow{2}{*}{\multicolumn{2}{|c|}{ Total }} \\
\hline & \multicolumn{2}{|c|}{ Male } & \multicolumn{2}{|c|}{ Female } & & \\
\hline & $\mathbf{n}$ & $\%$ & $\mathbf{n}$ & $\%$ & $\mathbf{n}$ & $\%$ \\
\hline 0 to 4 & 105 & 31.0 & 122 & 31.5 & 227 & 31.3 \\
\hline 5 to 8 & 106 & 31.3 & 120 & 31.0 & 226 & 31.1 \\
\hline 9 to 12 & 114 & 33.6 & 121 & 31.3 & 235 & 32.4 \\
\hline 13 to 19 & 14 & 4.1 & 24 & 6.2 & 38 & 5.2 \\
\hline Total & 339 & 100 & 387 & 100 & 726 & 100 \\
\hline
\end{tabular}

There were no differences between the two sexes regarding age ( $z=0.061$ and $p=.95$ in the Mann-Whitney $U$ test).

Of the total patients, $46.4 \%$ had hyperopia, $34.6 \%$ astigmatism, $13.2 \%$ strabismus, and $5.8 \%$ myopia, with $39.0 \%$ presenting other diagnoses. There was a significant variety; however, none surpassed $2.8 \%$ of the sample (i.e., all had only 20 cases or fewer). Only the diagnoses of refraction errors or heterotropia were considered frequent enough for statistical evaluations. $25.2 \%$ of the patients wore glasses, and $18.1 \%$ complained of headaches.

\section{Analysis}

Logistic regressions were used to measure the explanatory 
power of the independent variables in estimating the probability of headache while controlling for covariance effects. The first group of independent variables considered was: age, sex, use of glasses, headache complaint, and ocular diagnosis; the other group considering the variables: hyperopia, astigmatism, myopia, and strabismus. An index was created based on the regression results that differentiates those with a greater or lesser chance of headache based on the ocular diagnosis.

\section{Results}

Only the ocular diagnosis gave a significant association with headache as a function of sex, age, use of glasses, hyperopia, astigmatism, myopia, and strabismus (Table 2). Sex, age, and the use of glasses, on the other hand, did not emerge as having such an association when one controlled for the existence of refraction errors and strabismus.

Table 2. Logistic regression of headache complain as a function of sex, age, use of glasses, hyperopia, astigmatism, myopia, and strabismus

\begin{tabular}{|c|c|c|c|}
\hline \multicolumn{4}{|c|}{ Method: Quasi-Newton } \\
\hline \multicolumn{4}{|c|}{ Chi ${ }^{2}=93.442$ p $<.01$} \\
\hline Positivity $=15.3 \%$; Specificity $=97.3 \%$ \\
\hline Variable & Beta & Odds-Ratio & Wald chi-square (p) \\
\hline Female sex & 0.35 & 1.42 & 0.10 \\
\hline Age & 0.02 & 1.07 & 0.87 \\
\hline Use of glasses & -0.45 & 0.64 & 0.11 \\
\hline Myopia & 1.25 & 3.50 & 0.01 \\
\hline Hyperopia & 1.18 & 3.26 & $<0.01$ \\
\hline Astigmatism & 0.79 & 2.20 & $<0.01$ \\
\hline Strabismus & 1.78 & 5.93 & $<0.01$ \\
\hline Constant & 2.70 & & $<.01$ \\
\hline
\end{tabular}

The low sensitivity observed considering only hyperopia, astigmatism, myopia, and strabismus as independent variables can be explained by: (a) the relatively low incidence of headache $(18.0 \%)$ in the sample, and (b) the generic and unspecific nature of headaches as a symptom. Regardless of this, these findings demonstrate the existence of explanatory power of the ocular diagnosis when it comes to headaches (Table 3).

The odds ratios found for each of the diagnoses indicate the relative impact of each ocular diagnosis upon the probability of headache. Therefore, it may be said that strabismus has the most significant effect (5.21), followed by hyperopia (3.10), myopia (2.67), and, lastly, astigmatism (1.86).
Table 3. Logistic regression of headache complain as a function of hyperopia, astigmatism, myopia, and strabismus

\begin{tabular}{|c|c|c|c|}
\hline \multicolumn{5}{|c|}{ Method: Quasi-Newton } \\
\hline \multicolumn{4}{|c|}{$\mathrm{Chi}^{2}=88.232$ p<.01 } \\
\hline \multicolumn{4}{|c|}{ Sensitivity $=12.2 \%$; Specificity $=97.5 \%$} \\
\hline Positive Predictive Value = 51.6\%; Negative Predictive Value = 83.5\% \\
\hline Variable & Beta & Odds-Ratio & Wald chi-square (p) \\
\hline Myopia & 0.98 & 2.67 & 0.03 \\
\hline Hyperopia & 1.13 & 3.10 & $<0.01$ \\
\hline Astigmatism & 0.62 & 1.86 & 0.01 \\
\hline Strabismus & 1.65 & 5.21 & $<0.01$ \\
\hline Constant & 2.79 & & $<0.01$ \\
\hline
\end{tabular}

\section{Cumulative Impact of Refraction Errors and Strabismus}

The number of diagnoses of hyperopia, astigmatism, myopia, or strabismus on a given individual (HAMS Score) is a measure of the number of combined ocular disorders one may have. Roughly, $39.0 \%$ have a score of zero, $26.4 \%$ a score of one, $30.2 \%$ a score of two, and only $4.4 \%$ a score of three.

The HAMS Score can be used to determine the cumulative effect of refraction errors and heterotropia on the probability of headache, as shown in Figure 1.

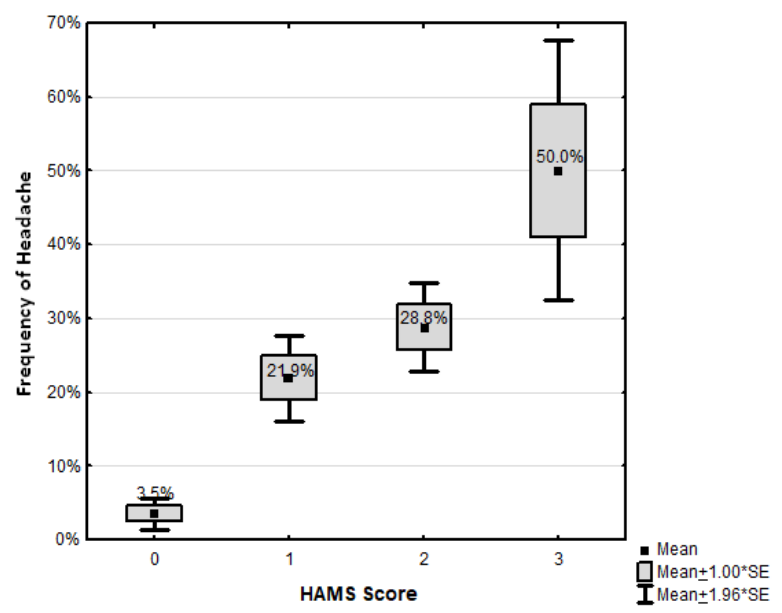

Figure 1. The frequency of children with headache in relation to the HAMS (Hyperopia, Astigmatism, Myopia, and Strabismus) Score.

One can see that there is a clear trend towards an increase in the incidence of headache as the HAMS Score gets higher, with the probability of headache being only 3.5\% when the score is zero but climbing as high as $50.0 \%$ when the score is three. This makes such a score a somewhat valuable tool. 
However, despite its usefulness and simplicity, the HAMS Score has the fundamental flaw of considering all four ocular diagnoses (i.e., hyperopia, astigmatism, myopia, and strabismus) as having equal weight. At the same time, the analysis in Table 4 clearly shows that this is not the case. One way to correct this is to create a version of the score where the weight of each component is given by the odds-ratio obtained in the logit regression so that a Weighed HAMS Score can be produced according to the following formula:

Weighed HAMS Score=5.21 *Strabism.+3.10+Hyperop. $+2.67 *$ Myop. $+1.86 *$ Astigm

For the sample studied, the distribution of the Weighed HAMS Score was such that $39.0 \%$ had a value of zero, $20.0 \%$ a value between 0.1 and $4.1,34.9 \%$ a value between 4.1 and 8.0 , and $6.2 \%$ a value of 8.1 or higher. Figure 2 shows the relationship between the Weighed HAMS Score and the incidence of headache in the present study.

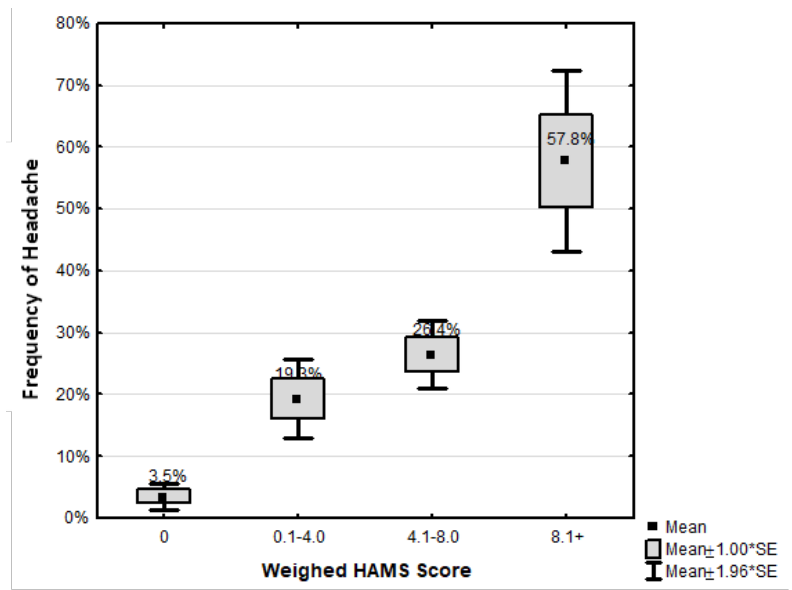

Figure 2. The frequency of children with headache in relation to the HAMS (Hyperopia, Astigmatism, Myopia, and Strabismus) Score.

In Figure 2, there is a clear trend towards an increase in the frequency of headache as the Weighed HAMS Score gets higher. The probability of headache was only $3.5 \%$ when the score was zero, but it became as high as $57.8 \%$ when the score was 8.1 or more. The Weighed HAMS Score has the advantage of producing a more significant differentiation between the probabilities of highest and lowest levels $(57.8 \%$ versus $3.5 \%$, a ratio of 16.51$)$ than the one obtained by the simple HAMS Score $(50.0 \%$ versus $3.5 \%$, a ratio of 9.43). Furthermore, the margin of error in the estimation of the probability of the highest level of the score was smaller in the case of the Weighed HAMS Score $(25.3 \%)$ than in the simple HAMS Score (35.2\%).

\section{Profile of pediatric patients with a high risk for headache of ocular origins}

Table 4 compares the patients with a score on the Weighed HAMS Scale that is equal to or greater than 8.1 with those with a score below 8.1, with regards to sex, age range, use of glasses, refractory errors, and strabismus. The patients with a higher Weighed HAMS Score were much more prone to experiencing headaches $(57.8 \%$ versus $15.4 \%)$. As to their other traits, statistical differences were found regarding:

Table 4. Comparison between patients with a higher (>8.1) and lower $(<8.1)$ Weighed HAMS (Hyperopia, Astigmatism, Myopia, and Strabismus) Score

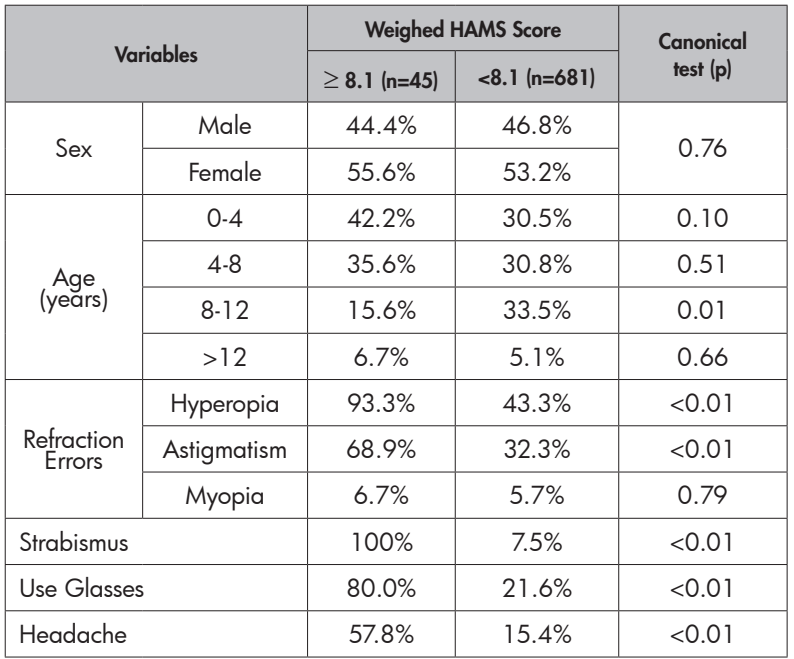

- Age: Among those with higher Weighed HAMS Score, there were fewer patients in the 8 to 12-year-old bracket and, marginally, more patients in the 0 to 4 -year-old range (adjusted $Z=-2.024$ and $p=.04$ on the Mann-Whitney $U$ test for the difference in age as a whole, with the higher Weighed HAMS Score group being younger);

Refraction Errors: The group with higher Weighed HAMS Score had a much greater proportion of patients with hyperopia (93.3\% versus $43.3 \%)$ and astigmatism (68.9\% versus $32.3 \%)$;

- Strabismus: All patients in the higher Weighed HAMS Score group (100\%) had strabismus, whereas there were only $7.5 \%$ of the lower Weighed HAMS Score group with this condition;

- Use of Glasses: About $80.0 \%$ of the high Weighed HAMS Score group wore glasses, while only $21.6 \%$ of the others did the same. 
Interestingly, though $100 \%$ of the high WBS group had strabismus, such group represents only $46.9 \%$ (45 out of 96) of all the patients with that condition.

\section{Discussion}

\section{Age, Sex, Glasses, and Headache}

Once one controlled covariance with other variables, particularly refraction errors and strabismus, there was no association between sex, age, glasses, and headache. This suggests that an increase in the prevalence of headaches in the female sex and older children might not be a consequence of sex and age per se, but rather the association between such things and other factors (covariance), particularly with ocular diagnoses. ${ }^{44-46}$

\section{Ocular Diagnoses and Headache}

Logistic regression of the incidence of headache as a function of the ocular diagnosis showed that strabismus was the strongest predictor of headaches (odds-ratio of 5.21), followed by hyperopia (odds-ratio of 3.10) and myopia (odds-ratio of 2.67), with astigmatism having the smallest impact (odds-ratio 1.86). This may be due to the specific mechanisms involved in such affections, such as the practical impact on vision and eyestrain.

It is important to note that only one-tenth of all the patients with headache at the ophthalmological service can be explained by ocular diagnoses, which is consistent with the existence of a myriad of causes of headache, and also with the fact that headaches in children and adolescents have a relatively low. ${ }^{39,44}$ However, such a percentage of patients with headache that can be predicted by ocular diagnoses is large enough to be relevant in clinical practice, and, as it will be discussed in the following subsection, there is a cumulative effect that, under certain conditions, are associated to a probability of more than $50 \%$ of a headache occurs.

\section{HAMS and the Cumulative Impact of Ocular Diagnoses}

The accumulation of HAMS diagnoses was shown to be associated with a fairly dramatic increase in the incidence of headache in this series (from $3.5 \%$ to $50.0 \%$, a relative risk of 9.43), especially when one ponders the individual impact of each specific diagnosis (from 3.5\% to $57.8 \%$, a relative risk of 16.51). ${ }^{39,46}$ Such a finding suggests that ocular problems, particularly refraction errors and strabismus, have a relevant impact on the occurrence of headache among children and adolescents, especially when such issues accumulate in the same patient. In the most extreme cases (Weighed HAMS Score >8.1), which encompass $6.2 \%$ of the patients studied, the probability of headache can be as high as $57.8 \%$, meaning that, for them, it is more likely that a headache will occur than that it will not.

\section{Profile of High-Risk Pediatric Patients}

Based on the Weighed HAMS Score, the present study results showed that pediatric patients at high risk for headaches of ocular origins tend to be younger, with a greater prevalence of those in early childhood than those above four. In terms of ocular health, all of them had strabismus (100\%), almost all had hyperopia (93.3\%), and more than two-thirds of them had astigmatism $(68.9 \%)$, which is why the vast majority wore glasses $(80.0 \%)$. Considering these findings, it would appear that younger patients with strabismus plus hyperopia and astigmatism, even though most of them already use corrective lenses, should be considered at high risk for suffering from headaches of ocular causes; thus requiring special attention on behalf of the ophthalmologist regarding the investigation of causes and planning of treatment, including the possibility of a consultation with a neurologist.

\section{Conclusion}

Is possible and relatively easy to construct an index based on the most common ocular diagnoses (Weighed HAMS Score), which is of practical application in identifying patients with a greater or lower propensity towards headaches of an ophthalmological origin. Ocular diagnoses, particularly hyperopia, astigmatism, myopia, and strabismus, seem to play a relevant cumulative role in the occurrence of headaches in children and adolescents, especially in the small number of patients where such ocular affections are combined to a significant degree. In this particular subgroup, it is more likely that headache episodes will occur.

The group of patients with a very high propensity for headache episodes is characterized by being younger, having a combination of strabismus, hyperopia, astigmatism, and already using corrective lenses. The risk is so significant that it should be presumed that these patients will have headaches. The accompanying measures of such an assumption (further investigation, treatment planning, consulting with other experts) appear to be taken by negligence. 
Future studies on the subject of the relationship between ocular diagnoses and headache should include a substantially larger series of patients than the present to allow for the evaluation of the impacts of ophthalmological diseases other than HAMS, as well as a more detailed description of the headache characteristics (intensity, location, duration) and the ocular health, along with data on treatments and outcomes, to provide a complete view of the phenomena observed, thereby allowing one to obtain findings capable of shedding light upon the possible mechanisms involved, as well as producing more accurate diagnostic and prognostic models, as well as profiles.

Conflict of interest: the authors declare no conflict of interest.

Funding: There was no funding for this research.

Author contributions: PTVVS, collected the data and paper draft; LPAAV, JRA and MMV carried out the review of the final version.

Paulo de Tasso Valença Veloso de Siqueira https://orcid.org/0000-0002-9570-6924 Luciana Patrízia Alves de Andrade-Valença https://orcid.org/0000-0002-3487-0325 Juliana Ramos de Andrade https://orcid.org/0000-0002-5445-8872 Marcelo Moraes Valença https://orcid.org/0000-0003-0678-3782

\section{References}

1. Chilaris GA. Headache of ocular origin. Gaz Med Fr 1954;61(10):685-686

2. Gifford ES, Jr. Headache of ocular origin. Gp 1954;9(4):55-57

3. Wyrick R. Diagnosis of ocular headache. J Okla State Med Assoc 1953;46(5):114-116

4. Dosal AF and Del Pinal JL. Headache of ocular origin. Clin Lab 1952;54(321):424-433

5. Ehlers H. Ocular headache. Manedsskr Prakt Laegegern 1951;29(3):108-114

6. Ruedemann AD. Headache and head pain of ocular origin. J Am Med Assoc 1950;144(7):517-519 Doi:10.1001/jama. 1950.02920070005002

7. Baker IS. Ocular headache. Optician 1947; 1 13(2926):267; passim

8. Baker IS. Ocular headache. Optician 1947; 113(2923):191; passim

9. Cooper EL. Ocular causes of headache. J Mich State Med Soc 1946; 45:485-488

10. Stewart DS. Ocular Headache. $\mathrm{Br}$ Med J
1937;2(3992):59-60 Doi:10.1136/bmi.2.3992.59

11. Fergus F. Headache and Ocular Treatment. Glasgow Med J 1908;70(5):321-338

12. Hinshelwood J. Some Observations on Ocular and Other Forms of Chronic Headache. Glasgow Med J 1904;61(1):7-19

13. Hinshelwood J. Ocular Headache. Glasgow Med J 1900;54(5):335-343

14. Mittendorf WF. Four thousand cases of Ocular Headache and the different states of refraction connected therewith. Trans Am Ophthalmol Soc 1895; 7:339-347

15. Cross FR. Asthenopia and Ocular Headache. Bristol Med Chir J (1883) 1893; 11(40):73-84

16. Higgens C. Ocular Headache. $\mathrm{Br}$ Med J 1883;1(1171):1115 Doi:10.1136/ bmj.1.1171.1115

17. Chamlin M. Headache of ocular origin. Int I Neurol 1962;3:360-367

18. Jampel RS. Ocular factors in headache. Headache 1965;5(3):82-86 Doi:10.1111/i.1526-4610.1965. hed0503082.x

19. Reddy SC. Ocular causes of headache and its management. J Indian Med Assoc 1980;75(2):34-36

20. MacCumber MW, Jaffe GJ and McCuen BW. Treatment of Migraine Headache After Ocular Surgery With Intravenous Metoclopramide Hydrochloride. Am J Ophthalmol 1996;121(1):96-97 Doi:10.1016/ S0002-9394(14)70542-2

21. Morell M, Clement E, Bernad MJ, Berbegal P and Soler S. A new type of headache of ocular origin: ophthalmotonic headache. Diagnosis and treatment. Rev Neurol 1997;25(146): 1557-1560

22. Daroff RB. Ocular causes of headache. Headache 1998; 38(9): 661 Doi: 10.1046/j.15264610.1998.3809661.x

23. Ringeisen AL, Harrison AR and Lee MS. Ocular and orbital pain for the headache specialist. Curr Neurol Neurosci Rep 2011;11(2):156-163 Doi:10.1007/ s11910-010-0167-6

24. Verdure $P$, Le Moigne $O$, Massardier EG, Vanhulle C, Tollard E and Maltête D. Migraine-like headache and ocular malformations may herald Moyamoya syndrome. Rev Neurol (Paris) 2012;168(5):460-461 Doi:10.1016/i.neurol.2011.09.011

25. Park $T$ and Choi $G$. Unilateral fronto-temporal headache with ocular pain caused by lens subluxation due to spontaneous zonulysis. Clin Exp Emergency Med 2015;2(2):133-136 Doi:10.15441/ ceem. 15.031

26. Hackett A, StuartJ, Blessing Nand Borden N. Headache with Aura: A case report of ocular melanoma. Am J 
Emerg Med 2018;36(11):2135.e2137-2135.e2138 Doi:10.1016/i.ajem.2018.08.047

27. Arruda MA, Arruda $R$, Guidetti $\vee$ and Bigal ME. Psychosocial adjustment of children with migraine and tension-type headache - a nationwide study. Headache 2015;55 Suppl 1:39-50 Doi:10.1111/head.12510

28. Arruda MA, Guidetti V, Galli F, Albuquerque RC and Bigal ME. Migraine, tension-type headache, and attention-deficit/hyperactivity disorder in childhood: a population-basedstudy. PostgradMed2010; 122(5): 18 26 Doi:10.3810/pgm.2010.09.2197

29. Arruda MA, Guidetti V, Galli F, Albuquerque RC and Bigal ME. Frequency of headaches in children is influenced by headache status in the mother. Headache 2010;50(6):973-980 Doi:10.1111/ i. 1526-4610.2010.01677.x

30. Dias MJM. Cefaleias na criança. Pediatria 1983;5(5):295-299

31. Gorayeb MAM and Gorayeb RJAdn-p. Association between headache and anxiety disorders indicators in a school sample from Ribeirao Preto, Brazil. Arq Neuropsiquiatr 2002;60(3B):764-768 Doi:10.1590/ S0004-282X2002000500016

32. Puccini RF and Bresolin AMB. Recurrent pain in children and adolescents. J Pediatria 2003;79:S65-S76 Doi:10.2223/iped. 1001

33. Oster J. Recurrent abdominal pain, headache and limb pains in children and adolescents. Pediatrics 1972;50(3):429-436

34. Mortimer MJ, Kay J, Gawkrodger DJ, Jaron A and Barker DC. The prevalence of headache and migraine in atopic children: an epidemiological study in general practice. Headache 1993;33(8):427-431 Doi:10.1111/j.1526-4610.1993.hed3308427.x

35. Gherpelli J. Treatment of headaches. J Pediatr 2002;78(Suppl 1):S3-8 Doi:10.2223/iped.844

36. Sillanpää $M$. Changes in the prevalence of migraine and other headaches during the first seven school years. Headache 1983;23(1):15-19 Doi:10.1111/i.1526-4610.1983.hed2301015.x
37. Mehboob MA, Nisar $\mathrm{H}$ and Khan M. Ametropia in children with headache. Pak J Med Sci 2019;35(3):701-704 Doi:10.12669/pims.35.3.268

38. Harle DE, Evans BJ and science v. The correlation between migraine headache and refractive errors. J Optometry 2006;83(2):82-87 Doi:10.1097/01. opx.0000200680.95968.3e

39. Roth Z, Pandolfo KR, Simon J and Zobal-Ratner J. Headache and refractive errors in children. $J$ Pediatr Ophthalmol Strabismus 2014;51(3):177-179 Doi: 10.3928/01913913-20140429-02

40. Hendricks TJ, J DEB, van Der Horst FG, Hendrikse $F$ and Knottnerus JA. Relationship between habitual refractive errors and headache complaints in schoolchildren. Optom Vis Sci 2007;84(2):137-143 Doi: 10.1097/OPX.0b013e318031b649

41. Dotan G, Stolovitch C, Moisseiev E, Cohen S and Kesler A. Uncorrected amteropia among children hospitalized for headache evaluation: a clinical descriptive study. BMC Pediatr 2014;14:241 Doi: 10.1186/1471-2431-14-241

42. Headache Classification Committee of the International Headache Society (IHS) The International Classification of Headache Disorders, 3rd edition. Cephalalgia 2018;38(1):1-211 Doi: $10.1177 / 0333102417738202$

43. Jeddi A, Ben Hadj Alouane W, Hammoud M, Malouch N, Zghal I, Ayed S and Zouari B. Full optical correction after cycloplegia in headache. J Fr Ophtalmol 2002;25(3):270-273

44. Akinci A, Güven A, Degerliyurt A, Kibar E, Mutlu $M$ and Citirik $M$. The correlation between headache and refractive errors. J aapos 2008; 12(3):290-293 Doi:10.1016/i.jaapos.2007.11.018

45. McKendrick AM and Nguyen BN. The eye in migraine: a review of retinal imaging findings in migraine. Clin Exp Optom 2021;1-8 Doi:10.1080/08164622.202 1.1971045

46. Importance of eye disease in headache. Emerg Nurse 1996;3(4):27 Doi:10.7748/en.3.4.27.s 14 